\title{
The influence of catalytic additives on kinetics of coal gasification process
}

\author{
Katarzyna Zubek ${ }^{1, *}$, Grzegorz Czerski $^{1}$, and Stanisław Porada ${ }^{1}$ \\ ${ }^{1}$ AGH University of Science and Technology, Faculty of Energy and Fuels, al. Mickiewicza 30, \\ 30-059 Krakow, Poland
}

\begin{abstract}
Catalytic coal gasification is a process that has the potential to become one of the efficient industrial technology of energy production. For this reason, the subject of this study was to analyze the kinetics of catalytic gasification of 'Janina' coal with steam. Isothermal measurements were performed at $800{ }^{\circ} \mathrm{C}, 900{ }^{\circ} \mathrm{C}, 950{ }^{\circ} \mathrm{C}$ and $1000{ }^{\circ} \mathrm{C}$ at a pressure of $1 \mathrm{MPa}$ using cations of sodium, potassium and calcium as catalysts. During examination the thermovolumetric method was used. This method allows to determine the formation rates of a gaseous product such as carbon monoxide, hydrogen, methane and carbon dioxide as well as their contribution to the resulting gas. Moreover, the influence of catalysts on the kinetics of $\mathrm{CO}$ and $\mathrm{H}_{2}$ formation at various temperatures was determined and the kinetics parameters were calculated with the use of isoconversional model, Random Pore Model and Grain Model. The obtained results confirmed the positive effect of catalysts on the coal gasification process. The catalytic measurements were characterized by higher reaction rate and shorter duration of the process, and the calculated values of the kinetic parameters were lower than for the gasification process without the addition of catalysts.
\end{abstract}

\section{Introduction}

The process of coal gasification with steam is a well-known technology, the basics of which were formed during the production of town gas at the turn of the 19th and 20th centuries. The production of gas from coal has been supplanted by the use of natural gas and has become a technology with limited uses. Along with the technical advances, interest in the gasification process returned, due to environmental concerns and the search for new, sustainable ways of energy production. Gasification is a clean and effective process of gas generation that may be used to produce power, chemicals or synthetic fuels. Moreover, this technology allows decreasing greenhouse gas emissions, in particular $\mathrm{CO}_{2}$ [1]. Because of that numerous works aimed at improving gasification process are conducted. The use a variety of gasifying agents, operating conditions, types of fuel as well as catalysts are analyzed [2-7]. This research is particularly important in the case of fluidized bed reactors operating at low temperatures, where the high reactivity of the fuel is essential to ensure the efficient course of the process. Numerous of works confirmed the influence of catalysts on increasing the process rate or

\footnotetext{
*Corresponding author: kzubek@agh.edu.pl
} 
changing the resulting gas composition [8-10]. Currently, due to the high efficiency and low price, catalysts based on alkali and alkaline earth metals have gained the greatest popularity $[11,12]$. However, research is continually conducted in order to find new solutions, such as catalysts based on noble or transition metals $[13,14]$. In order to use catalyst on an industrial scale, beyond the high catalytic activity it should be characterized by the low price. This condition is not fulfilled in the case of noble metals. Catalysts based on transition metals are much cheaper, but at high temperatures quickly become deactivated and their regular exchange or activation significantly increase the costs of their use $[15,16]$. Besides the type of the catalyst, an important factor determining its effect on the reaction is a method of adding catalytically active material to the feedstock. This occurs generally in two ways: by wet impregnation and the physical mixing [17]. The most important advantage of the first method is the ability to ensure good contact between coal and catalyst [18]. However, physical mixing is characterized by simplicity and short execution time, moreover certainty that the amount of catalyst will be exactly as established [19]. The addition of catalytically active substances improves the process efficiency as a result of changes in the kinetics, resulting in the reduction of activation energy. Therefore, there is a necessity to analyze the kinetics of coal gasification with catalysts in order to determine their impact on the process. This is an important step providing information needed to design gasifiers. The complexity of the gasification, intensified by the addition of catalyst makes that kinetics of this process is still a current issue which requires further research.

The aim of this study was to analyze the kinetics of gasification of 'Janina' coal with cations of sodium, calcium and potassium, which were introduced by the wet impregnation method. Isothermal measurements were conducted at $800^{\circ} \mathrm{C}, 900{ }^{\circ} \mathrm{C}, 950{ }^{\circ} \mathrm{C}$ and $1000{ }^{\circ} \mathrm{C}$ under a pressure of $1 \mathrm{MPa}$ with the use of the thermovolumetric method, developed by AGH. On the basis of the obtained results the influence of catalysts on the gasification process was determined, the formation rate of the individual components of synthesis gas, as well as its composition was defined. With the use of isoconversional method the values of activation energy were calculated and these results were compared with the kinetic parameters calculated on the basis of Random Pore Model (RPM) and Grain Model (GM).

\section{Material and methodology}

\subsection{Characteristic of material}

Coal from the Polish mine 'Janina' was selected as feedstock for the research. Samples with a particle size below $0.2 \mathrm{~mm}$ and a weight of $1 \mathrm{~g}$ were used in the measurements. The results of proximate and ultimate analysis, as well as the composition of 'Janina' coal ash are summarized in Table 1.

Table 1. Characteristic of 'Janina' coal.

\begin{tabular}{cc|cc|cc}
\hline \multicolumn{5}{c}{ Parameter } \\
\hline Proximate analysis & $\mathbf{( \% w t )}$ & Ultimate analysis & $\mathbf{( \% w t )}$ & Ash composition & $\mathbf{( \% w t )}$ \\
\hline Moisture - $\mathrm{M}^{\mathrm{a}}$ & 8.7 & Carbon - $\mathrm{C}^{\text {daf }}$ & 77.8 & $\mathrm{SiO}_{2}$ & 59.4 \\
Ash - $\mathrm{A}^{\mathrm{a}}$ & 14.0 & Hydrogen - $\mathrm{H}^{\text {daf }}$ & 3.9 & $\mathrm{Al}_{2} \mathrm{O}_{3}$ & 23.3 \\
Volatile Matter - & 46.1 & Sulfur - $\mathrm{S}^{\mathrm{a}}$ & 1.0 & $\mathrm{Fe}_{2} \mathrm{O}_{3}$ & 8.2 \\
$\mathrm{VM}^{\text {daf }}$ & & & $\mathrm{MgO}$ & 1.2 \\
& & & $\mathrm{CaO}$ & 2.2 \\
& & & $\mathrm{~K}_{2} \mathrm{O}$ & 2.9 \\
& & & $\mathrm{Na}_{2} \mathrm{O}$ & 2.8 \\
\hline
\end{tabular}


Ions of alkali and alkaline earth metals - sodium, potassium and calcium, introduced by wet impregnation method were used as catalytically active materials. Obtained samples of coal contained $3 \%$ wt. of the corresponding metal.

\subsection{Methodology of measurements}

Description of the laboratory equipment on which the measurements were carried out has been presented in previous publications [20,21], and its schematic diagram is shown in Figure 1.

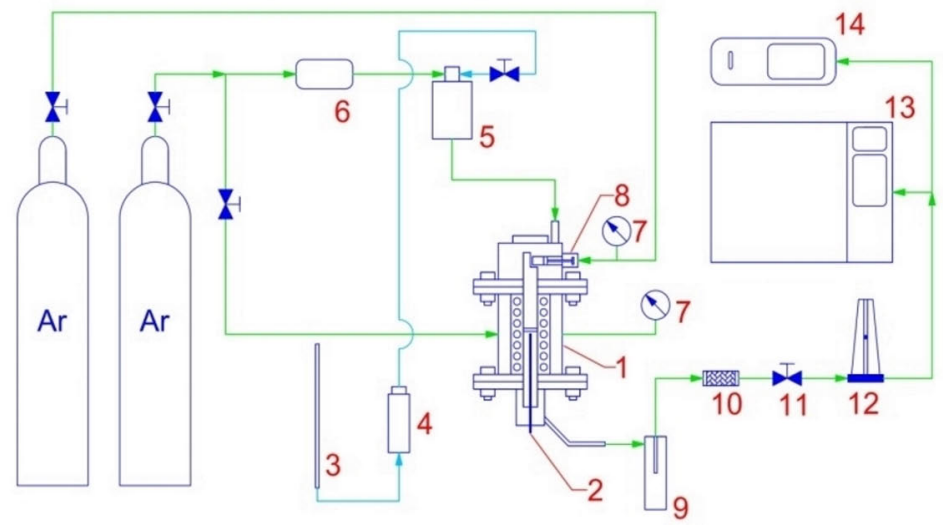

Fig. 1. The laboratory equipment for kinetic examinations of coal gasification process.

1 - reactor, 2 - thermocouple, 3 - water tank, 4 - water pump, 5 - steam generator, 6 - mass flowmeter, 7- pressure gauge, 8 - coal feeder, 9 - cooler, 10 - filter, 11 - pressure regulator, 12 - rotameter, 13 gas chromatograph, $14-\mathrm{CO}, \mathrm{CO}_{2} \mathrm{IR}$ analyser [20,21].

The equipment consists of several basic systems: a pressure reactor with a heating system (1-2), a system for feeding the reactor with the gasifying agent - steam (3-5), carrier gas argon (6-7), and coal (8), system for collecting and purifying the resulting gas (9-11) and the gas analysis system (12-14). In the resulting gas the content of carbon monoxide, carbon dioxide and methane was continuously controlled by analyzer operating on the principle of infrared radiation adsorption. In addition, the content of hydrogen was analyzed using gas chromatograph equipped with thermal conductivity detector (TCD).

Isothermal measurements of the kinetics gasification process were carried out at $800{ }^{\circ} \mathrm{C}, 900{ }^{\circ} \mathrm{C}, 950{ }^{\circ} \mathrm{C}$ and $1000{ }^{\circ} \mathrm{C}$ under an elevated pressure of $1 \mathrm{MPa}$. The weight of the sample fed into the reaction zone was $1 \mathrm{~g}$, steam flow was $0.3 \mathrm{~g} / \mathrm{min}$, while the argon flow was $2 \mathrm{dm}^{3} / \mathrm{min}$.

\subsection{Methodology of kinetics parameters calculation}

Based on the concentrations of the main components of the gas $\left(\mathrm{CO}, \mathrm{H}_{2}, \mathrm{CO}_{2}, \mathrm{CH}_{4}\right)$ the formation rates of these gaseous products, as well as their contribution to the resulting gas were determined. During the measurements the time required to transfer gas from the reaction zone into the analyzer has been taken into account.

The reactions of formation of carbon monoxide and hydrogen may be expressed as:

$$
X(t)=\frac{V_{x(t)}}{V_{x(\text { total })}}
$$


where: $V_{x(t)}$ is a volume of $\mathrm{CO}$ or $\mathrm{H}_{2}$ formed from the beginning of the reaction to time $\mathrm{t}$, $\mathrm{dm}^{3} / \mathrm{g}, V_{x(t o t a l)}$ is the total volume of $\mathrm{CO}$ or $\mathrm{H}_{2}$ formed during the whole reaction, $\mathrm{dm}^{3} / \mathrm{mol}$.

The effect of temperature and concentration of gaseous reactant on the gasification process rate can be expressed by the equation (2):

$$
\frac{d X}{d t}=k(T) G(C) f(X)
$$

where: $\mathrm{k}$ and $\mathrm{G}$ are the rate constants, dependent on temperature $\mathrm{T}$ and reagent concentration $\mathrm{C}$ and $\mathrm{f}(\mathrm{X})$ accounts for physical or chemical changes occurring with the progress of the reaction. The apparent reaction rate constant $\mathrm{k}(\mathrm{T})$ and the concentration of the reagent $\mathrm{G}(\mathrm{C})$ are generally described in the form of an Arrhenius equation (3):

$$
k(T) G(C)=A e^{\frac{-E_{a}}{R T}} C^{n}
$$

where: $A$ is a pre-exponential factor, $E_{a}$ is activation energy and $n$ is an order of the reaction, taking into account the concentration of the gas reactant.

In order to analyze the kinetics of the gasification process, two approaches were used. Firstly, isoconversional method, which allows to determine the activation energy was applied. Combining and integrating equations 2 and 3, provides equation 4 which describe isoconversional method:

$$
\ln (t)=\ln \left(\frac{F(X)}{C^{n} A}\right)+\frac{E_{a}}{R T}
$$

Equation 4 allows to determine the activation energy from the slope of $\ln (t)=f(1 / T)$ for $\mathrm{X}=$ $0.25,0.5,0.75$, even though $f(X)$ in equation 2 is unknown.

In the second approach two models, usually used to describe heterogeneous gas-solid reaction were used, i.e. Grain Model (GM) and Random Pore Model (RPM). Experimental data were analyzed in the range of $\mathrm{CO}$ and $\mathrm{H}_{2}$ formation reactions degree from 0 to $80 \%$.

The GM model assumes that the reaction occurs at the external surface of the char particle and surface area decreases non-linearly as the reaction proceeds, and RPM model assumes that the reaction surface changes as a result of two competing processes: the increase of the pore structure during gasification and its destruction due to coalescence of adjacent pores. GM and RPM models are described respectively by equations 5 and 6 .

$$
\begin{gathered}
\frac{\mathrm{dX}}{\mathrm{dt}}=\mathrm{k}_{\mathrm{GM}}(1-\mathrm{X})^{\frac{2}{3}} \\
\frac{\mathrm{dX}}{\mathrm{dt}}=\mathrm{k}_{\mathrm{RPM}}(1-\mathrm{X}) \sqrt{1-\Psi \cdot \ln (1-\mathrm{X})}
\end{gathered}
$$

where: $\Psi$ is associated with the pore structure of the material [22].

\section{Results and discussion}

During steam gasification process coal is transformed into gas, which is composed mainly of $\mathrm{CO}$ and $\mathrm{H}_{2}$. However, as a result of a number of parallel reactions various gaseous products are also formed, among others methane and carbon dioxide. The changes in the formation rates of $\mathrm{CO}, \mathrm{H}_{2}, \mathrm{CO}_{2}$ and $\mathrm{CH}_{4}$ during the gasification of the examined samples at the temperature of $800{ }^{\circ} \mathrm{C}$ are shown in Figure 2. 

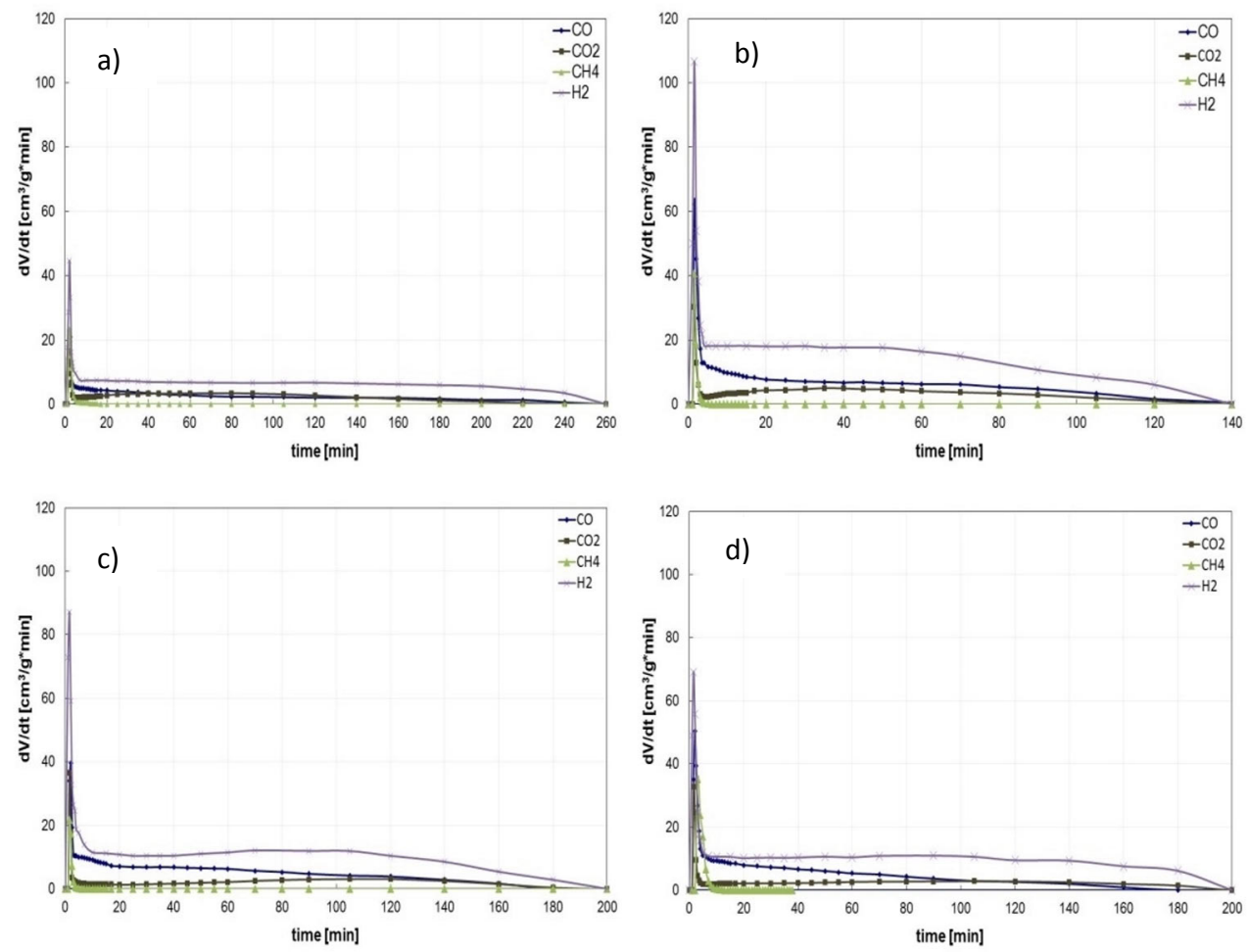

Fig. 2. The changes in the formation rates of gaseous products during the gasification of a) coal; b) coal with $\mathrm{Na}^{+}$; c) coal with $\mathrm{K}^{+}$; d) coal with $\mathrm{Ca}^{2+}$.

The whole process can be divided into two stages: pyrolysis and gasification of previously formed char. During the pyrolysis formation rates of gaseous products are the highest, which can be observed in the first minutes of the process. Then there is much slower gasification stage.

During the whole process of coal gasification without the catalyst, the formation rate of hydrogen was the highest, higher more than twice than very similar formation rates of carbon monoxide and carbon dioxide. The last of the analyzed components - methane was formed with a relatively high rate, but its release was limited only to the pyrolysis stage. The obtained results confirmed the positive effect of catalysts on the gasification process. The addition of the cations of sodium, potassium and calcium substantially catalyzed the pyrolysis stage, resulting in a marked increase in formation rates of all the gaseous products in the initial stage of the process. During the char gasification stage increased formation rates of the basic components of gas i.e. $\mathrm{CO}$ and $\mathrm{H}_{2}$ can be observed as a result of the addition of the catalysts. The average $\mathrm{CO}$ formation rate during the catalytic gasification was almost two times higher than in the case of coal gasification without a catalyst. However, the predominant gaseous product was still hydrogen, the formation rate of which increased, in particular in the case of using sodium ions as a catalyst. The average formation rate of hydrogen during the catalytic gasification was more than 2 times higher when the coal was impregnated with sodium ions and more than 1.5 during the gasification with $\mathrm{Ca}^{2+}$ - catalyst which the slightest improved the formation rate of $\mathrm{H}_{2}$ at $800{ }^{\circ} \mathrm{C}$ compared to the non-catalytic gasification process. The addition of catalytically active materials had not a significant impact on the formation rates of carbon dioxide and methane, which proves that these catalysts mainly catalyze the reaction of gasification of element $\mathrm{C}$ with steam. 
The composition of the gas obtained from gasification of 'Janina' coal allows to assess the impact of the individual catalysts on the process at a given temperature and it is shown in Table 2. The accuracy of $\mathrm{CO}$ and $\mathrm{CO}_{2}$ measurements was $\sim 5 \%$, while $\mathrm{CH}_{4}$ and $\mathrm{H}_{2}$ was $\sim 1 \%$.

Table 2. The composition of the resulting gas.

\begin{tabular}{llllll}
\hline 'Janina' & \multicolumn{2}{l}{ Temperature } & \multicolumn{2}{l}{ Share $[\%]$} \\
\cline { 2 - 5 } coal & {$\left[{ }^{\circ} \mathrm{C}\right]$} & $\mathrm{CO}$ & $\mathrm{H}_{2}$ & $\mathrm{CO}_{2}$ & $\mathrm{CH}_{4}$ \\
\hline without catalyst: & 800 & 21.2 & 57.8 & 19.4 & 1.6 \\
& 900 & 24.3 & 58.3 & 15.7 & 1.7 \\
& 950 & 28.7 & 56.0 & 13.2 & 2.1 \\
with catalyst: & 1000 & 34.8 & 55.4 & 8.1 & 1.7 \\
$>\quad \mathrm{Na}^{+}$ & & & & & \\
& 800 & 25.2 & 59.7 & 14.0 & 1.1 \\
& 900 & 28.6 & 58.7 & 11.5 & 1.2 \\
& 950 & 33.2 & 55.9 & 9.4 & 1.4 \\
$>\mathrm{K}^{+}$ & 1000 & 30.3 & 58.7 & 9.6 & 1.4 \\
& & & & & \\
& 800 & 31.3 & 56.1 & 11.9 & 0.7 \\
& 900 & 34.0 & 55.5 & 9.0 & 1.5 \\
& 950 & 33.7 & 56.4 & 8.7 & 1.2 \\
$>\mathrm{Ca}^{2+}$ & 1000 & 34.2 & 55.8 & 8.5 & 1.5 \\
& & & & & \\
& 800 & 26.5 & 57.7 & 14.3 & 1.5 \\
& 900 & 30.5 & 57.3 & 10.7 & 1.4 \\
& 950 & 32.5 & 55.1 & 10.6 & 1.8 \\
& 1000 & 33.2 & 55.6 & 9.5 & 1.8 \\
\hline
\end{tabular}

The contribution of hydrogen to the resulting gas from 'Janina' coal gasification was the largest and represented from $55 \%$ to $60 \%$, depending on the analyzed case. There was no clear effect of temperature or catalyst on the share of $\mathrm{H}_{2}$ released in the process. With rising temperature the share of carbon monoxide increased in each case at the expense of carbon dioxide, enhancing the calorific value of the resulting gas. This phenomenon was most evident during the gasification of coal without the catalysts, where the contribution of $\mathrm{CO}$ and $\mathrm{CO}_{2}$ at the lowest temperature was almost identical. This may be caused by an exothermic, reversible reaction of conversion of carbon monoxide with steam, the equilibrium of which is shifted towards the substrate the more the higher is the temperature of the process, as well as by the Boudouard reaction. The addition of catalysts resulted in an increased share of the carbon monoxide in the resulting gas at a given temperature as compared with the non-catalytic coal gasification carried out under similar conditions. The contribution of $\mathrm{CO}$ to the resulting gas was the highest in the case of coal gasification with potassium ions added. The addition of $\mathrm{Ca}^{2+}$ or $\mathrm{Na}^{+}$resulted in gas with a similar share of $\mathrm{CO}$, but lower than in the case of utilization of $\mathrm{K}^{+}$. Exceptions were the measurements carried out at $1000{ }^{\circ} \mathrm{C}$ in which the composition of resulting gas was almost identical in each case. Neither temperature nor addition of the catalysts affected the share of methane, whose contribution to the resulting gas was negligible due to its formation only during the pyrolysis stage.

The next step was to present the progress of the reaction of main products formation, expressed as a function of released $\mathrm{CO}$ and $\mathrm{H}_{2}$ at the time. Gasification, as an example of a highly endothermic reaction, proceeds faster with increasing temperature. A similar effect gave the addition of the catalysts. Effect of catalytic additives on the process, expressed 
as a function of the formation of $\mathrm{CO}$ at various temperatures was shown in Figure 3. At $800{ }^{\circ} \mathrm{C}$ the impact of the catalysts was the most visible. All considered catalytic additives accelerated the reaction, simultaneously reducing process time and the most active catalyst was sodium. With the increase of temperature to $950^{\circ} \mathrm{C}$ catalytic gasification proceeded more efficiently compared to the non-catalytic process, and the effect of the addition of sodium and calcium ions was very similar. The least effective catalyst was potassium. At $1000{ }^{\circ} \mathrm{C}$ the addition of the catalysts was unfounded because the non-catalytic process was more efficient. This effect may be associated with the interaction of mineral matter with catalytic additives, which at high temperatures leads to the formation of complex compounds inhibiting the gasification process [23].
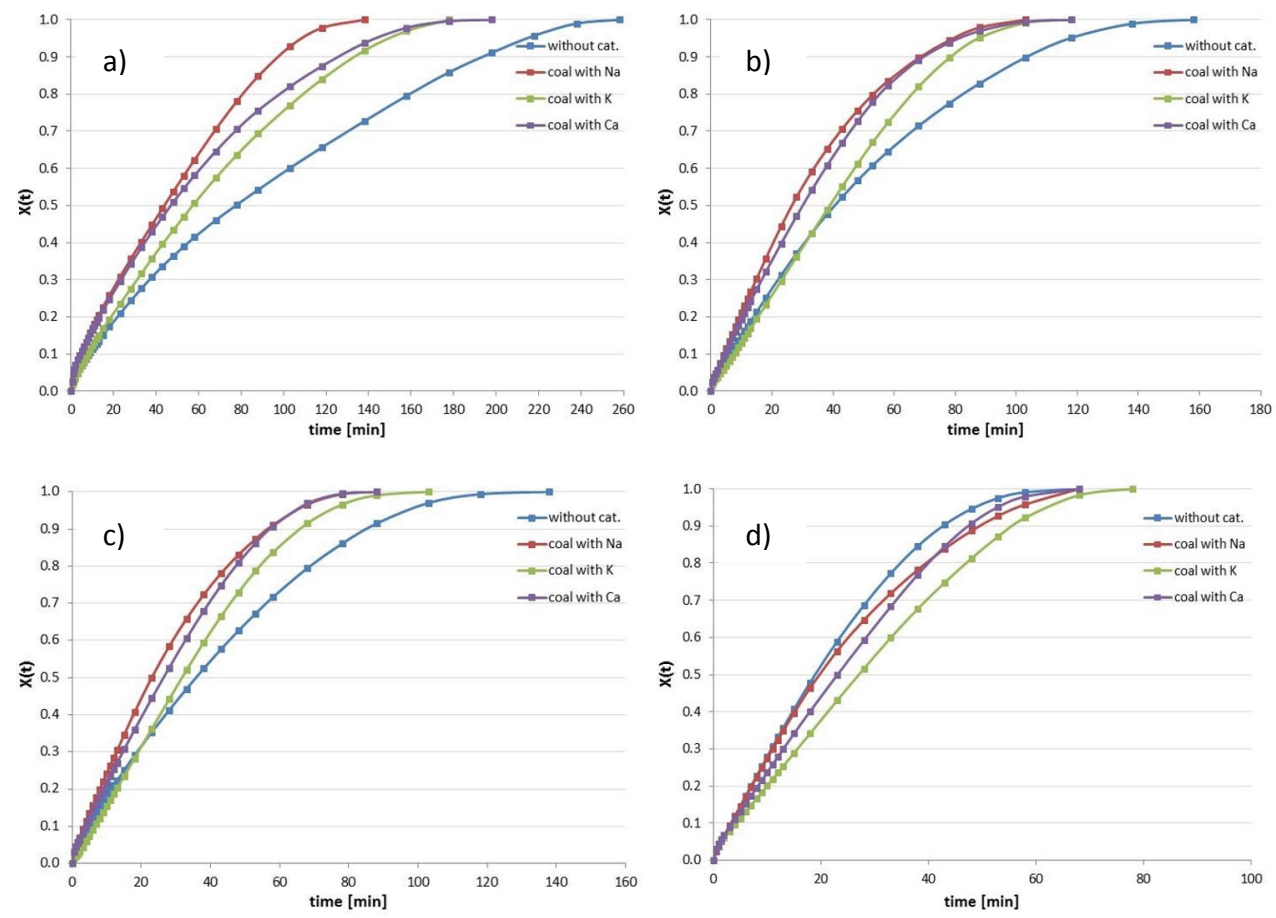

Fig. 3. Effect of catalysts on $\mathrm{CO}$ formation reaction at a) $800{ }^{\circ} \mathrm{C}$; b) $900{ }^{\circ} \mathrm{C}$ c) $\left.950{ }^{\circ} \mathrm{C} \mathrm{d}\right) 1000{ }^{\circ} \mathrm{C}$.

The addition of sodium most effectively influenced on the reaction of $\mathrm{H}_{2}$ formation, while the effect of calcium and potassium was very similar in all tested temperatures, as shown in Figure 4. As already mentioned, during catalytic coal gasification at $1000{ }^{\circ} \mathrm{C}$ compounds inhibiting the process rate may be formed. This phenomenon could influence on the reaction of $\mathrm{H} 2$ formation at the highest analyzed temperature. Practically the whole process of noncatalytic gasification was faster than the gasification with $\mathrm{K}^{+}$or $\mathrm{Ca}^{2+}$. However, the best of the catalysts $-\mathrm{Na}^{+}$increased the rate of the gasification process. Nevertheless, due to the fact that the positive effect of sodium on the progress of $\mathrm{CO}$ formation reaction at $1000{ }^{\circ} \mathrm{C}$ was not observed, catalytic gasification at temperatures above $950{ }^{\circ} \mathrm{C}$ is not a preferred solution. 

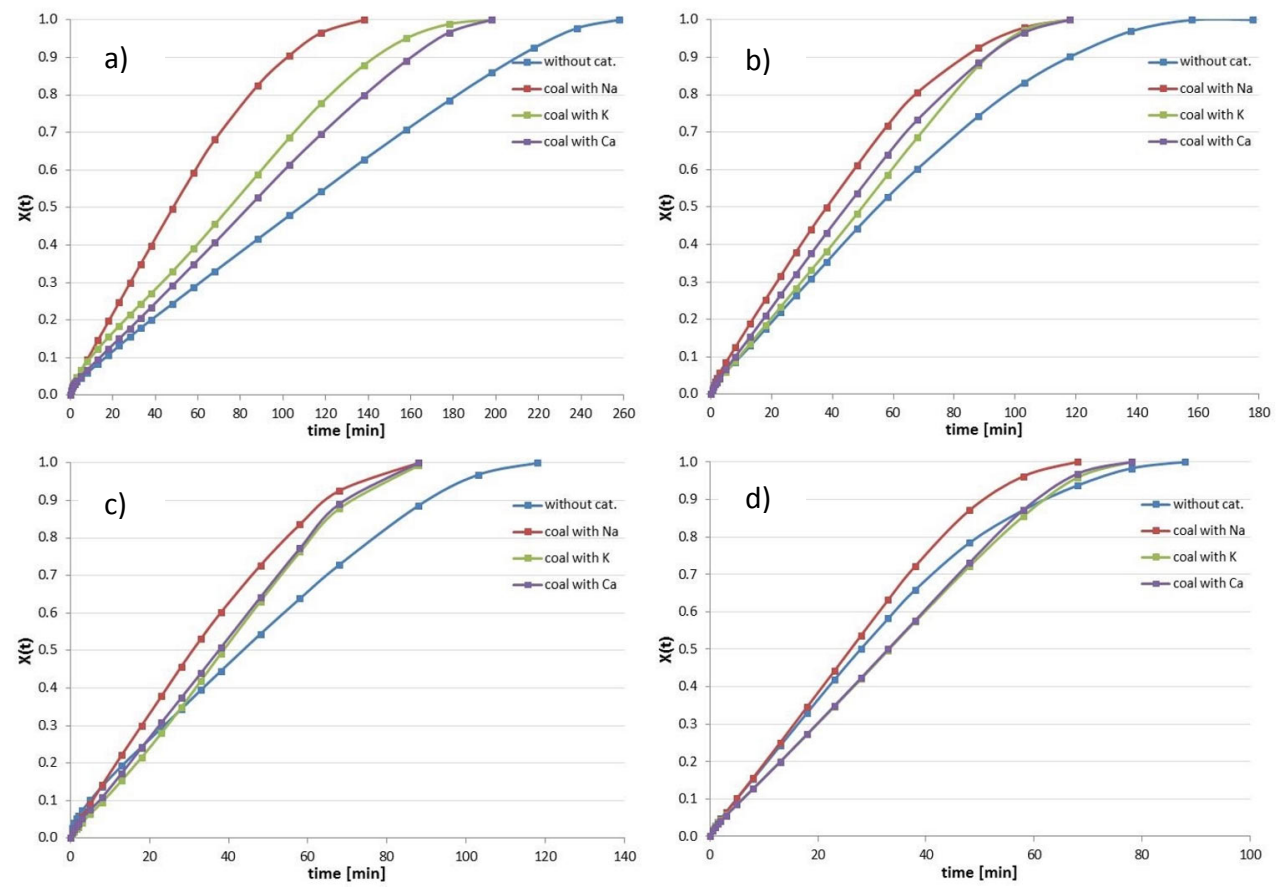

Fig. 4. Effect of catalysts on $\mathrm{H}_{2}$ formation reaction at a) $800^{\circ} \mathrm{C}$; b) $900{ }^{\circ} \mathrm{C}$ c) $950{ }^{\circ} \mathrm{C}$ d) $1000{ }^{\circ} \mathrm{C}$.

Another step of this work was to determine the kinetic parameters of the gasification process. With the use of isoconversional method the values of activation energy of $\mathrm{CO}$ and $\mathrm{H}_{2}$ formation reactions were calculated and the obtained results are summarized in Table 3 .

Table 3. Values of activation energy calculated with the use of isoconversional method.

\begin{tabular}{ccr}
\hline 'Janina' coal & $\mathrm{CO}$ & $\mathrm{H}_{2}$ \\
\cline { 2 - 3 } & $\mathrm{E}_{\mathrm{a}}[\mathrm{kJ} / \mathrm{mol}]$ & $\mathrm{E}_{\mathrm{a}}[\mathrm{kJ} / \mathrm{mol}]$ \\
\hline without catalyst & $72.0 \pm 8.8$ & $72.8 \pm 1.4$ \\
with addition of: & & \\
$>\mathrm{Na}^{+}$ & $41.5 \pm 4.5$ & $34.8 \pm 1.6$ \\
$>\mathrm{K}^{+}$ & $43.6 \pm 5.1$ & $48.3 \pm 1.4$ \\
$>\mathrm{Ca}^{2+}$ & $40.1 \pm 9.0$ & $54.0 \pm 1.6$ \\
\hline
\end{tabular}

'Janina' coal was characterized by high reactivity as evidenced by relatively low values of the calculated activation energy. Activation energies of $\mathrm{CO}$ and $\mathrm{H}_{2}$ formation during noncatalytic coal gasification were the highest and simultaneously very similar. The addition of catalysts caused their significant reduction in a various way. The values of activation energy of $\mathrm{CO}$ formation were similar irrespective of the catalyst used and ranged between 40.1 and $43.6 \mathrm{~kJ} / \mathrm{mol}$. This lack of difference could be caused by the fact that the calculated values were vitiated by relatively large errors. Moreover, the obtained $\mathrm{E}_{\mathrm{a}}$ of $\mathrm{CO}$ formation included a series of reactions that took place during the gasification process, in which the $\mathrm{CO}$ was created. The various effect of tested catalysts on these reactions could lead to similar values of $E_{a}$. In the case of $E_{a}$ of $\mathrm{H}_{2}$ formation differences were much bigger - from 34.8 using $\mathrm{Na}^{+}$ as a catalyst to 54.0 using ions of calcium. This sequence could result from the fact that the sodium ions (to a lesser extent potassium ions) may catalyze the water gas shift reaction $[24,25]$. The results confirmed the catalytic activity of alkali and alkaline-earth metals in the 
gasification process, wherein the sodium more effectively catalyzed the reaction of $\mathrm{H}_{2}$ formation than the reaction of $\mathrm{CO}$ formation, the effect of potassium on the formation of both gaseous product was comparable, while calcium was more effective in the reaction of $\mathrm{CO}$ formation. In order to obtain the values of both kinetic parameters: activation energy - $E_{a}$ and pre-exponential factor - A, two additional models i.e. Random Pore Model and Grain Model were used, and the results are shown in Table 4.

Table 4. Values of kinetics parameters calculated with the use of GM and RPM.

\begin{tabular}{|c|c|c|c|c|}
\hline \multirow{3}{*}{ 'Janina' coal } & \multicolumn{2}{|c|}{$\mathrm{CO}$} & \multicolumn{2}{|c|}{$\mathbf{H}_{2}$} \\
\hline & $\mathbf{A}[\mathbf{1} / \mathbf{m i n}]$ & $\mathrm{E}_{\mathbf{a}}[\mathrm{kJ} / \mathrm{mol}]$ & A [1/min] & $\mathrm{E}_{\mathrm{a}}[\mathrm{kJ} / \mathrm{mol}]$ \\
\hline & \multicolumn{4}{|l|}{ Grain Model } \\
\hline without catalyst & $57.9 \pm 5.7$ & $80.3 \pm 13.5$ & $20.2 \pm 2.5$ & $72.4 \pm 8.8$ \\
\hline \multicolumn{5}{|l|}{ with addition of: } \\
\hline$>\mathrm{Na}^{+}$ & $2.3 \pm 0.6$ & $45.3 \pm 3.0$ & $0.6 \pm 0.3$ & $33.4 \pm 4.5$ \\
\hline$>\mathrm{K}^{+}$ & $2.7 \pm 0.8$ & $48.8 \pm 3.2$ & $2.2 \pm 0.8$ & $48.4 \pm 3.9$ \\
\hline$>\mathrm{Ca}^{2+}$ & $2.9 \pm 0.9$ & $48.5 \pm 5.0$ & $3.1 \pm 1.1$ & $52.5 \pm 5.2$ \\
\hline \multicolumn{5}{|c|}{ Random Pore Model } \\
\hline without catalyst & $48.4 \pm 4.8$ & $80.2 \pm 13.6$ & $17.4 \pm 2.4$ & $72.5 \pm 8.8$ \\
\hline \multicolumn{5}{|l|}{ with addition of: } \\
\hline$>\mathrm{Na}^{+}$ & $2.0 \pm 0.6$ & $45.5 \pm 2.9$ & $0.5 \pm 0.2$ & $33.8 \pm 4.4$ \\
\hline$>\mathrm{K}^{+}$ & $2.1 \pm 0.7$ & $48.3 \pm 3.3$ & $1.9 \pm 0.7$ & $48.6 \pm 3.7$ \\
\hline$>\mathrm{Ca}^{2+}$ & $2.5 \pm 0.9$ & $48.6 \pm 5.1$ & $2.9 \pm 1.3$ & $53.1 \pm 6.0$ \\
\hline
\end{tabular}

The values of $E_{a}$ calculated on the basis of RPM and GM models were almost identical, and were within the margin of error of which the results calculated from isoconversional method were burdened. Calculated values of A were also similar regardless of the model used, but the differences were greater than in the case of activation energy. The highest value of A was obtained for reaction of $\mathrm{CO}$ formation during non-catalytic gasification. In this process the value of $\mathrm{A}$, calculated for the reaction of $\mathrm{H}_{2}$ formation was much lower, although activation energies were not significantly different. The addition of catalysts decreased the values of pre-exponential factor. The results obtained for the reaction of $\mathrm{CO}$ formation during the catalytic gasification process were very similar. In case of reaction of $\mathrm{H}_{2}$ formation differences appeared, but were consistent with the changes in the values of the activation energy.

\section{Conclusion}

The measurements of catalytic coal gasification allowed to draw the conclusion that catalysts used in this work have a positive impact on the process. During the gasification of 'Janina' coal $\mathrm{H}_{2}$ and $\mathrm{CO}$ were the main products and the rate of hydrogen formation was almost twice as high as carbon monoxide. The addition of each catalyst resulted in an increase in the formation rates of these gaseous products, particularly in the case of using sodium ions as a catalyst. These findings were confirmed by kinetics parameters calculated on the basis of all the models used. Values of kinetics parameters were considerably lower in the case of catalytic gasification than the process without a catalyst. The use of catalysts resulted in an increased share of $\mathrm{CO}$ in the resulting gas compared to analogous non-catalytic measurements in the temperature range from 800 to $950{ }^{\circ} \mathrm{C}$. This effect was also observed with increasing temperature of the measurements. However, the addition of the catalyst at $1000{ }^{\circ} \mathrm{C}$ was unfounded, since did not improve the efficiency of the process. Nevertheless, as the purpose of the use of a catalyst is to improve the process rate at low temperatures, the obtained results are satisfactory and promising. These findings are particularly important in 
the case of gasification in fluidized bed reactors, operating at low temperatures since they indicate that the use of catalysts based on alkali and alkaline-earth metals significantly improves their work.

The work was conducted within the framework of the grant no. 15.11.210.336.

\section{References}

1. M. Pańczyk, T. Borowiecki, Adsorbenty i katalizatory. Wybrane technologie a środowisko, 2, 275-288 (2012)

2. T. Kyotani, K. Kubota, J. Cao, H. Yamashita, A. Tomita, Fuel Process. Technol. 36, 209-217 (1993)

3. C. Li, J. Zhao, Y. Fang, Y. Wang, Front. Chem. Eng. China. 4, 385-393 (2010)

4. K. Jayaraman, I. Gokalp, Fuel 153, 320-327 (2015)

5. X. Hung, F. Zhang, M. Fan, , Sustainable Catalytic Processes 7, 179-199 (2015)

6. D.J. Marchand, E. Schneider, B.P. Williams, Y.L. Joo, J. Kim, G.T. Kim, S.H. Kim, Fuel Process Technol. 130, 292-298 (2015)

7. C.L. Spiro, D.W. McKee, P.G. Kosky P.G, E.J. Lamby, Fuel 62(2), 180-184 (1983)

8. W.W. Li, K.Z. Li, X. Qu, R. Zhang, Fuel Process. Technol. 126, 504-512 (2014)

9. A. Sharma, T. Takanohashi, K. Morishita, T. Takarada, Fuel 87, 491-497 (2008)

10. F. Huhn, J. Klein, H. Jüntgen, Fuel 62(2), 196-199 (1983)

11. J. Tang J. Wang, Fuel Process. Technol. 142, 34-41 (2016)

12. Z.L. Liu, H.H. Zhu, Fuel 65(10), 1334-1338 (1986)

13. X. Qi, X. Guo, L. Xue, C. Zheng, C. J. Anal. Appl. Pyrol. 110, 401-407 (2014)

14. K. Otto, M. Shelef, Carbon 15(5), 317-325 (1977)

15. S. Ratchahat, S. Kodama, W. Tanthapanichakoon, H. Sekiguchi, Int. J. Hydrogen Energ. 40(35), 11809-11822 (2015)

16. I.G. Lee, A. Nowacka, C.H. Yuan, S.J. Park, J.B. Yang, Int. J. Hydrogen Energ. 40(36), 12078-12087 (2015)

17. J. Kopyscinski, R. Rahman R. Gupta, C. Mims, J. Hill, Fuel 117, 1181-1189 (2014)

18. C.L. Spiro, D.W. McKee, P.G. Kosky, E.J. Lamby, Fuel 63(5), 686-691 (1984)

19. C. Phuhiran, T. Takarada, Int. J. Hydrogen Energ. 39(8), 2649-3656 (2014)

20. S. Porada, G. Czerski, P. Grzywacz, T. Dziok, Przem. Chem. 93, 2059-2063 (2014)

21. S. Porada, G. Czerski, T. Dziok, P. Grzywacz, D. Makowska, Fuel Process. Technol, 130, 282-291 (2015)

22. G. De Micco, A. Nasjleti, A.E. Bohé, Fuel 95, 537-543 (2012)

23. J. Tang, J. Wang, Fuel Process. Technol. 142, 34-41 (2016)

24. J. Pazmino, M. Shekhar, W. Wiliams, C. Atakay, J. Miller, Catal. 286, 279-286 (2012)

25. B. Zugic, D. Bell, M. Flytzani-Stephanopoulos, Appl. Catal.,B. 144, 243-251 (2014) 